\title{
Replace and rebuild: Chinese colonial housing in Uyghur communities*
}

Timothy A. Grose

\begin{abstract}
rom Khan Tengri to the Kunlun Mountains, Uyghur homes are being transformed from the inside out. Snaking alleys connecting mähällä ('communities') are being buried beneath rows of high-rise apartments and tract-housing developments. Walls that once displayed beautiful woven giläm ('rugs') and delicate fabrics are now covered by Chinese national flags and images of President Xi Jinping. Raised platforms, or supa, which were used for eating, sleeping, and entertaining, are being smashed to clear space for chairs, sofas, and tables. Officially, the Chinese Communist Party boasts that these changes help rescue Uyghurs from poverty and propel them into modernity. However, these measures betray the hallmarks of colonisation: they are part of a process that destroys indigenous cultures to replace them with the values, sensibilities, and practices of the colonisers (Wolfe 2006).
\end{abstract}

\section{Domestic colonisation}

This strategy is neither new nor distinct to the CCP; it is critical to all colonial projects. Indeed, expanding empires and nationalising states have routinely regarded indigenous spaces as disorderly, unhygienic, and unsafe, and therefore in need of transformation (Glover 2007; Mitchell 1991). Meanwhile, cities, parks, courthouses, government housing, and public spaces of the metropole are inscribed with symbols of state authority, which legitimise its power to rule over communities (Dovey 1999: 10-13). Colonial configurations of order are also imposed at the family level. From French designs of Egyptian villages that were 'very neat' (Mitchell 1991: 44) to the construction of concrete structures for Aboriginal families in

"This chapter is based on the article 'IfYou Don't Know How, Just Learn: Chinese Housing and the Transformation of Uyghur Domestic Space', published in Ethnic and Racial Studies (vol. 40, no. I I, 202 I: 2052-73). 
Victoria, Australia (Healy 2019), and the introduction of 'practice cottages' to Native American boarding school students in Flandreau, North Dakota (Child 1998: 80-81), control of domestic space is critical for the imposition of colonial projects-often carried out by politically and economically disadvantaged members of the metropole-and provides opportunities for indigenous resistance (Stoler 2010).

Despite uneven outcomes, these historical examples reveal common motivations among colonisers: they attempt to regulate daily life. Foucault (1991) defines this general process as 'government rationality' or the social and political structures that create, mould, and groom upstanding citizens. Within the domain of the home, Timothy Mitchell (1991: 44) proposes thinking of these policies and practices as 'enframing' or 'dividing up and containing, as in the ... rebuilding of villages, which operates by conjuring up a neutral surface or volume called "space". Enframing instils order through two steps: 1) imposing microphysical power or regulation of behaviour brought about from the reordering of space, and 2) creating metaphysical power or instilling the deeply held belief that this order is natural and eternal (Mitchell 1991: 93-94). Put another way, enframing controls physical mobility and conditions the mind to accept these constraints as normal. Mitchell's theory can be aptly applied to Chinese state-mandated changes to Uyghur homes.

\section{Uyghur homes before Chinese colonisation}

The CCP is in the process of eliminating and replacing Uyghur configurations of the home. Before the peoples and places of the Tarim and Junggar basins-modern-day Xinjiang-were incorporated into the People's Republic of China, the region's residential architecture changed in line with cultural currents (Mähsut and Mähsut 2000). As the area’s peoples sedentarised, urbanised, and converted en masse to Islam, their physical dwellings began to reflect their faith as well as their incorporation into a Central Asian milieu (Tursuntohti 2013: 46-50).

A mental blueprint of a typical rural Uyghur house illuminates a matrix comprising intersecting physical and cultural boundaries (Dautcher 2009: 11-22). Family members and guests enter the courtyard (hoyla) and outdoor pavilion (aywan) from adjacent roads through a large, often two-door, wide gate (därwaza). The house's interior is commonly divided and arranged into formal entertaining rooms (saray/mehmanxana), common rooms (dalan), bedrooms (yataq öy), and kitchens (ashxana). 
In some houses, mehrab (arches or niches) are carved in the wall facing the direction of Mecca-that is, the qibla - and are used to store bedding (orun-körpä) and religious articles (Tursuntohti 2013: 48).

The saray is reserved for formal gatherings and special occasions. Marking a home's place of prestige, the saray's construction is distinct from other rooms and it is usually equipped with alcoves (oyuq-täqchä) that store and display delicate porcelain, vases, and linens. Meanwhile, the dalan functions to strengthen bonds among the immediate family, distant relatives, and neighbours. Reflecting this purpose, the dalan is animated with constant activity (Dautcher 2009: 13-14).

The supa stands at the centre of domestic life and hospitality. It also marks the house's tör, or place of honour (Tursuntohti 2013: 55). Interior supa are built of earth-or, less often, lumber-and raised 40-50 centimetres from the ground. The supa fulfils essential roles for extending and strengthening social networks beyond the genealogical family to more indigenous concepts of local belonging such as relatives (tughqan), neighbours (koshna), and community members (hekemsaye) (Steenberg 2014: 174-75). Often the site of naming ceremonies, sünnät circumcisions, nikah marriage vows, and other life-cycle rituals (toy), the supa also effectively blurs divisions between the sacred and the profane.

\section{Rapidly 'beautifying [Uyghur] spaces'}

CCP officials regard Uyghur homes and local domesticity as impediments to Han-defined secular modernity. A branch party secretary in Qaghliq County, Kashgar, insisted:

In the past, the situation of rural households was relatively poor: they didn't cultivate good living habits, most houses lacked beds, not to mention any other furniture. Families just slept on the floors or on mats on their supa; some didn't even wash them regularly. These habits are unhygienic, unhealthy, and contrary to a modern, civilised lifestyle. (China Kashgar Net 2018)

In a policy framed as 'poverty alleviation' (扶贫), the CCP has insisted on moving Uyghur families into Han-style homes to 'improve' their lives.

Although these efforts began in the 1980s and 1990s (Dautcher 2009: 29; Kobi 2016: 126-29, 2018: 214), the CCP has acted with greater urgency since 2017. Of course, that year witnessed the incarceration of Xinjiang's 
Turkic populations at alarming rates (Zenz 2019). Outside these reeducation centres, China's top brass set in motion a series of policies that have demolished and rebuilt Uyghur spaces. During his opening address at the Nineteenth Congress of the CCP on 18 October 2017, President Xi announced his 'Beautiful China' (美丽中国) initiative, which intended, among other goals, to raise environmental awareness and improve basic sanitation practices across the country (Beh 2017).

Officials in Xinjiang invoked Xi's speech to justify several 'beautification' programs in Uyghur communities. A government brief from Yarkand County cites Xi's call to 'accelerate the reform of [China's] ecological civilisation system, [and] build a beautiful China, before adding that 'beautifying rural villages is an important part of building a beautiful China' (Ma and Lin 2018). This abstract pledge solidified into concrete action before the 2018 Lunar New Year, when cadres introduced the 'Three New' campaign (三新活动). At the core of this multifaceted endeavour is 'advocating a new lifestyle, establishing a new atmosphere, and constructing a new order' (People’s Daily 2018).

\section{'Three new' to replace the 'old'}

The 'Three New' campaign's 'Establishing a New Atmosphere' (树立新 气象) initiative inspired the 'Beautifying Spaces' (美丽庭院) program. The first step in this beautification campaign is rearranging residential structures in a floorplan with 'three separate spaces' (三区分离). This model demands constructing clearly defined living quarters (生活区), spaces for small gardens (种植区), and areas for rearing domesticated animals (养殖区) to replace current house designs (Ma and Lin 2018). The standardised blueprint replicates government-built housing in rural Han-majority villages in eastern and central China. In fact, the Khotan Daily (2018) compares the results of its city's housing projects-displayed with before and after photographs-with those carried out in Han areas.

Reframing Uyghur homes into discrete domestic compartments requires the absence (or removal) of the structure that blurs physical, social, and religious-cultural boundaries: the supa. Some officials have even called for all supas to be 'demolished' (拆除) (Zero Distance Kashgar 2018). A Uyghur-language post from the county government in Maralbeshi County demanded that residents 'smash up' (qeqish) their supa and refuse to lay out mats and rugs (Zero Distance Maralbeshi 2018). Unquestionably, the supa has been singled out as a symbol of backward Uyghur customs, 
even though, in northern China, Han families regularly use the similar kang (炕) fixture in their homes. Yet in Xinjiang, interior supas have been deemed unhygienic, inconvenient, and detrimental to physical and mental wellness.

The destruction of the supa allows us to revisit Mitchell's discussion of 'enframing' or the colonial process of elimination and replacement. According to Mitchell's theory (1991: 93-94), when Han cadres remove the supa, they effectively eliminate the space that connects the sacred and the profane. They then replace the supa with tables and chairs - that is, discrete (and secular) spaces designed for individuals and only a few activities. In the end, these Han workers, through the introduction of furniture, impose a new ordering of space.

The project also aims to eliminate important symbolic markers that orient Uyghurs towards the Islamic world. Newly built and renovated houses are also devoid of mehrab arches/niches. Radio Free Asia (2019) reports that residents in Ili, Kashgar, and Khotan prefectures have been forced to either destroy mehrab carvings or fill them in because officials have deemed them 'extremist'; houses are demolished if the mehrab is part of a weight-bearing wall and cannot be removed. Although I have been unable to find government documents to corroborate this claim, I can confirm that mehrab cannot be found in the dozens of photographs depicting newly built and renovated living spaces.

Furniture provided by the nearly 1.1 million 'big brothers and sisters' sent to rural Xinjiang to live among Uyghur families fills otherwise empty concrete rooms (Byler 2018). According to the CCP, dining tables, coffee tables, sofas, and beds assume the power to acquaint residents with a 'new life' (Zero Distance Konashähär 2018) and establish 'scientific, civilised, and healthy' (ilmiy, mädäniy, and saghlam) living standards (Zero Distance Maralbeshi 2018). Officials in Kona Shärä even proclaim that 'civilisation begins at the dinner table' (Ma and Lin 2018) - a reference to interiors sans supa.

\section{Dismantling Uyghur space, regulating Uyghur pace}

The three-separate-spaces arrangement drastically alters Uyghur templates of domestic spatial organisation. Drawing on Glover's (2007: 139) analysis of the reordering of houses in Lahore, Pakistan, we learn that clearly delineating areas for living, farming, and animal rearing serves to isolate specific activities and objects to specialised spaces to increase domestic 
efficiency. The result, according to Glover (2007: 139), is 'the formation of new domestic sensibilities, habits, and sentiments that would be cultivated and disciplined in the newly remade spaces of the home. Newly remodelled homes and the rearrangement of domesticity introduce a Han-dominated, government-defined rationality of space and movement.

Similarly, new furniture is not meant to merely update aesthetics; rather, these fittings are meant to act on Uyghur world views. Glover (2007: xx) argues that colonisers 'shared an assumption that the material world embodied immaterial qualities that were both tangible and agentive'. According to this logic, material objects-as something that can be seen, touched, moved, and so on-affect and can even make predictable the behaviours of the agents who manipulate them. Seemingly informed by this belief, officials in Yarkand proclaim that 'modern furniture not only gives home interiors a brand-new look, it functions more to greatly elevate the quality of living' (Yarkand County Radio and TV 2018b).

These remarks bring into sharp relief the greater purpose of the program: 'civilising' Uyghurs. Government-mandated transformations of Uyghur domestic space are a part of the CCP's broader efforts to increase 'civilisation' (文明) in society and improve the individual quality (素质, or suzhi) of its citizens. Construction projects in China specifically seek to enhance the interconnected concepts of material (物质) and spiritual (精 神) civilisation and suzhi (Cliff 2016: 34). From the perspective of the CCP, state-built housing, replete with modern amenities, can help propel all communities towards the nation's 'epistemological centre of civilisation': urbanite Han people (Moreno 2018: 28-29). In other words, the furniture, according to this official, creates the 'civilised' (Han) environment that enhances the suzhi of local Uyghurs.

\section{Invisible violence, visible punishments}

As a 'project of improvement' - both material and individual-colonial housing is meant to appear less violent than other assimilatory programs (Mitchell 1991: 44). Glover (2007: xxi) is unequivocal: the introduction of new material objects in Lahore houses was 'largely meant to persuade, rather than force social change, thus distinguishing this method from Foucault's (1984: 179-87) 'disciplinary' practices, or the various programs of physical and mental subjugation imposed on a population to increase human efficiency. Yet, CCP housing policies in Uyghur communities fuse these two methods of inculcating compliance. That is, the state is using 
new materials-introducing standardised construction plans, beds, desks, and so on, while removing indigenous orderings of space, such as supa and mehrab-as tangible and agentive objects that seek to 'modernise' Uyghur lives. Put another way, the 'Three New' project-along with other colonial campaigns-destroys to replace (Wolfe 2006). However, as human agents of the state, the more than one million sent-down 'relatives' enforce compliance, document infractions, and punish insubordination (Byler 2018).

Those failing to conform to the party's standards are ostracised and punished. A party branch deputy secretary in Tageairike village, Khotan, reports that village cadres conduct random inspections each week to determine compliant and deviant households, which are then marked with, respectively, red or black banners (Zero Distance Päyzawat 2018). In Maralbeshi County, weekly village meetings announce blacklisted households, who are given a deadline by which to correct violations. Families placed on the blacklist three times are paraded on stage (亮相) in front of their peers, where they promise to rectify their faults. Officials are confident that public shaming will help villages establish a morality system under which 'poverty is disgraceful, wealth is honourable, laziness is shameful, and diligence is glorified' (Livestock Office of the XUAR 2018). The fear of incarceration will coerce families into conformity; otherwise, they will be removed from society.

\section{Eliminating the native}

This essay has introduced and examined the CCP's 'Three New' campaign as colonial practice. Although publicly described as poverty elimination, these construction projects impose immediate and, from the CCP's calculations, permanent changes on Uyghur perceptions of order, domestic space, and modernity. These spatial transformation programs are often essential components of centralised, comprehensive strategies to 'eliminate' the native. In other words, Wolfe (2006: 388-89) urges us to analyse cultural and racial elimination as a 'structure, not an event' - that is, an ongoing project that destroys, rebuilds, replaces, and renames. State-led housing projects in Uyghur communities destroy indigenous orderings of space and replace them with newly built structures originally designed for Han nuclear families. The physical, social, and conceptual changes spurred by the Three New campaign decode the Uyghur homeland and remap it more legibly into the CCP-imagined 'Xinjiang'. 

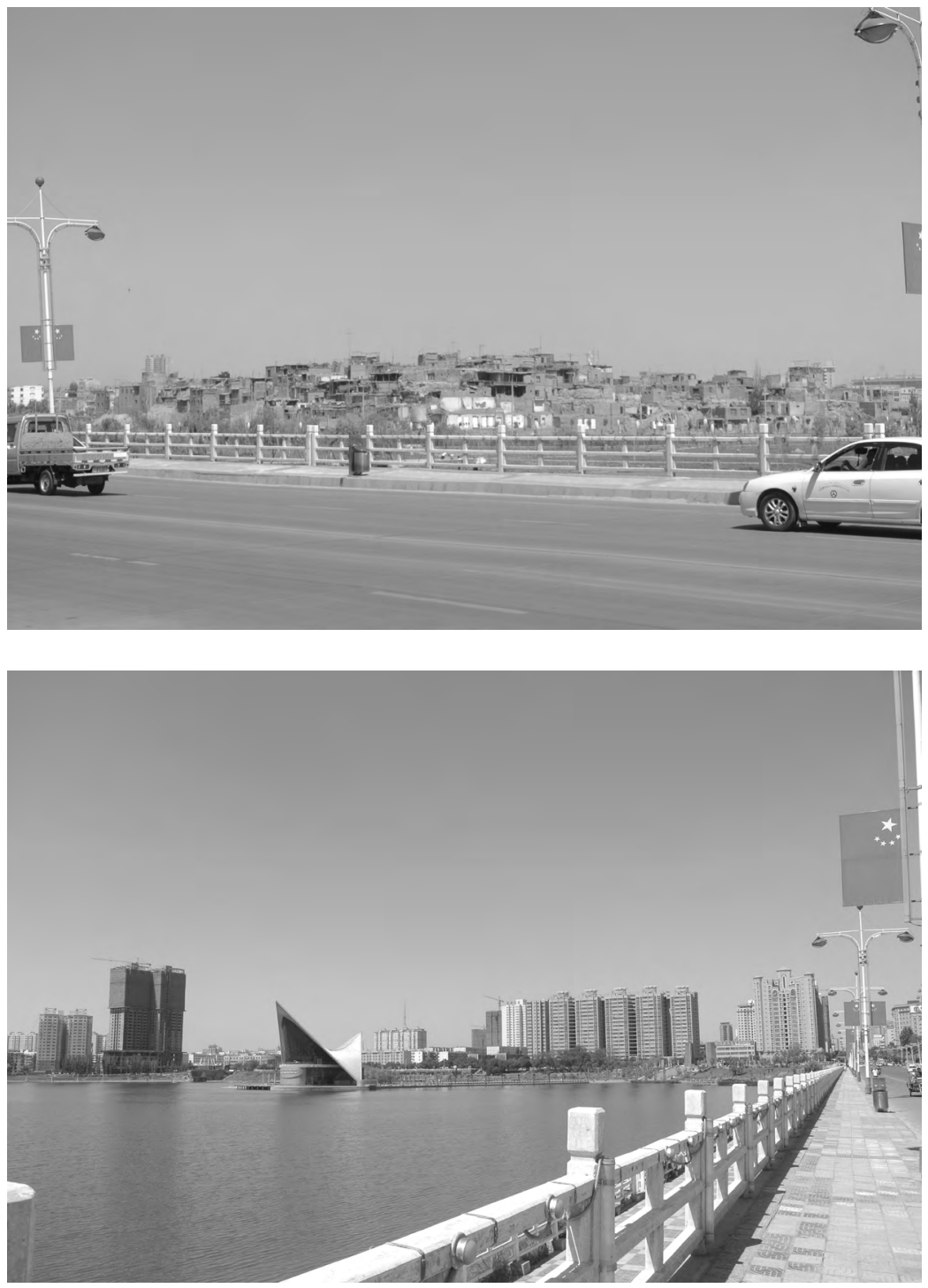

(Top) Plate 9.I Kashgar's 'Old Town', 2013. (Bottom) Plate 9.2 New housing developments in Kashgar, 2013. 

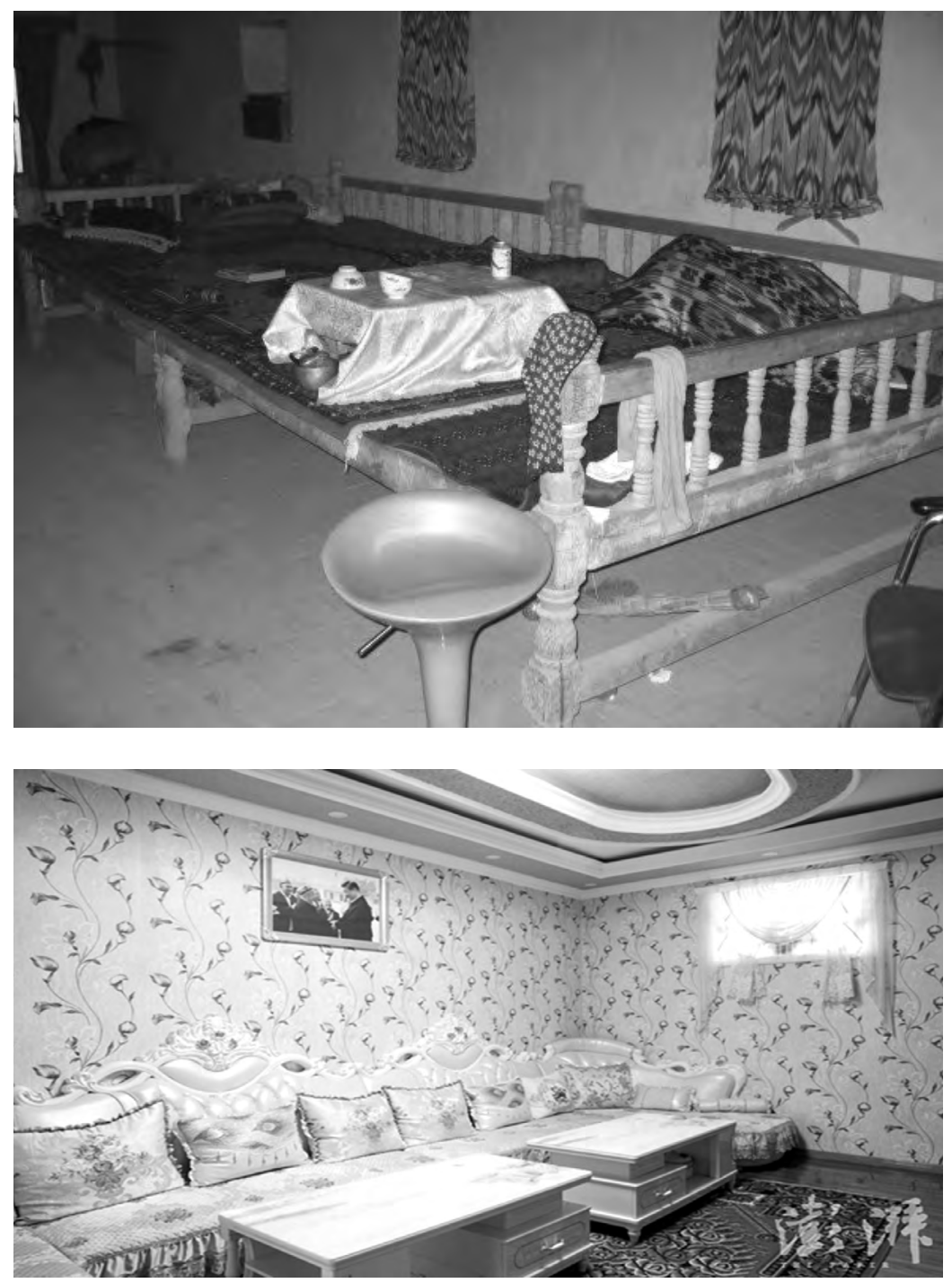

(Top) Plate 9.3 Family interior supa in rural Turpan. (Bottom) Plate 9.4 Newly built interior family room with picture of President $\mathrm{Xi}$. 
126 XINIIANG YEAR ZERO
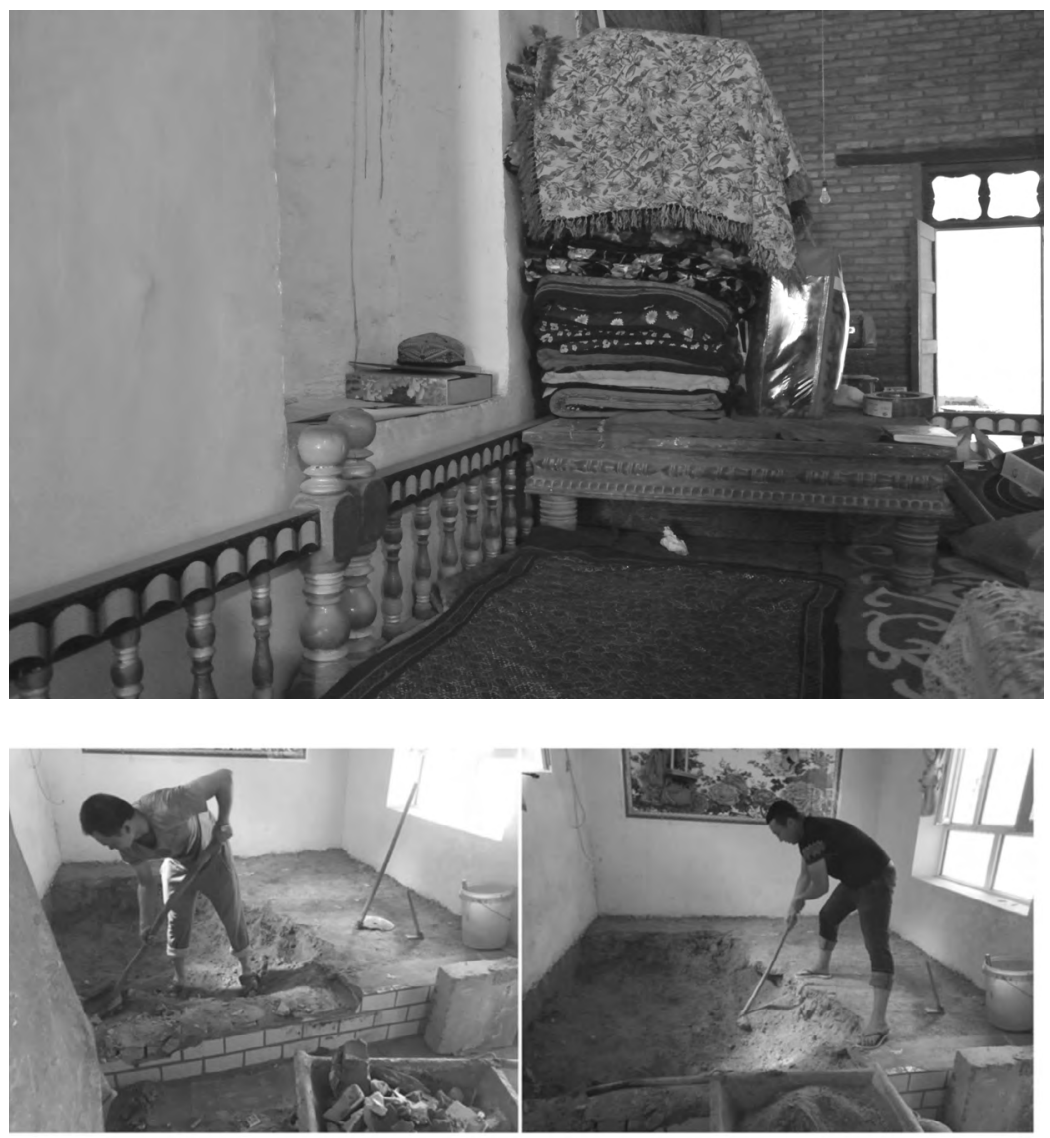

(Top) Plate 9.5 Mehrab in rural Turpan home. (Bottom) Plate 9.6 A work team destroys family supa. 
This text is taken from Xinjiang Year Zero, edited by Darren Byler, Ivan Franceschini and Nicholas Loubere, published 2022, The Australian National University, Canberra, Australia.

doi.org/10.22459/XYZ.2021.09 